NASA/TM-2000-210333

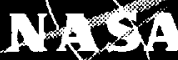

Transverse Magnetic Field Propellant Isolator

John E. Foster

Glenn Research Center, Cleveland, Ohio 
The NASA STI Program Office ... in Profile

Since its founding, NASA has been dedicated to the advancement of aeronautics and space science. The NASA Scientific and Technical Information (STI) Program Office plays a key part in helping NASA maintain this important role.

The NASA STI Program Office is operated by Langley Research Center, the Lead Center for NASA's scientific and technical information. The NASA STI Program Office provides access to the NASA STI Database, the largest collection of aeronautical and space science STI in the world. The Program Office is also NASA's institutional mechanism for disseminating the results of its research and development activities. These results are published by NASA in the NASA STI Report Series, which includes the following report types:

- TECHNICAL PUBLICATION. Reports of completed research or a major significant phase of research that present the results of NASA programs and include extensive data or theoretical analysis. Includes compilations of significant scientific and technical data and information deemed to be of continuing reference value. NASA's counterpart of peerreviewed formal professional papers but has less stringent limitations on manuscript length and extent of graphic presentations.

- TECHNICAL MEMORANDUM. Scientific and technical findings that are preliminary or of specialized interest, e.g., quick release reports, working papers, and bibliographies that contain minimal annotation. Does not contain extensive analysis.

- CONTRACTOR REPORT. Scientific and technical findings by NASA-sponsored contractors and grantees.
- CONFERENCE PUBLICATION. Collected papers from scientific and technical conferences, symposia, seminars, or other meetings sponsored or cosponsored by NASA.

- SPECIAL PUBLICATION. Scientific, technical, or historical information from NASA programs, projects, and missions, often concerned with subjects having substantial public interest.

- TECHNICAL TRANSLATION. Englishlanguage translations of foreign scientific and technical material pertinent to NASA's mission.

Specialized services that complement the STI Program Office's diverse offerings include creating custom thesauri, building customized data bases, organizing and publishing research results ... even providing videos.

For more information about the NASA STI Program Office, see the following:

- Access the NASA STI Program Home Page at http://www.sti.nasa.gov

- E-mail your question via the Internet to help@sti.nasa.gov

- Fax your question to the NASA Access Help Desk at (301) 621-0134

- Telephone the NASA Access Help Desk at (301) 621-0390

- Write to: NASA Access Help Desk NASA Center for AeroSpace Information 7121 Standard Drive Hanover, MD 21076 
NASA/TM-2000-210333

(स)

.

\section{Transverse Magnetic Field Propellant Isolator}

John E. Foster

Glenn Research Center, Cleveland, Ohio

National Aeronautics and

Space Administration

Glenn Research Center 
Available from

NASA Center for Aerospace Information 7121 Standard Drive

Hanover, MD 21076

Price Code: A03
National Technical Information Service 5285 Port Royal Road Springfield, VA 22100 Price Code: $\mathrm{A} 03$ 


\title{
TRANSVERSE MAGNETIC FIELD PROPELLANT ISOLATOR
}

\author{
John E. Foster \\ National Aeronautics and Space Administration \\ Glenn Research Center \\ Cleveland, Ohio 44135
}

\section{SUMMARY}

An alternative high voltage isolator for electric propulsion and ground-based ion source applications has been designed and tested. This design employs a transverse magnetic field that increases the breakdown voltage. The design can greatly enhance the operating range of laboratory isolators used for high voltage applications.

\section{INTRODUCTION}

Ion sources used for space propulsion or ground-based plasma processing require the plasma production chamber to be isolated from the gas feed system which is typically at ground potential (either earth or spacecraft ground depending on the application). In this respect an isolator is required to not only provide high voltage isolation, but also allow gas flow between a large potential difference without breaking down. ${ }^{1,2}$ Figure 1 illustrates the role of such an isolator for an ion thruster application. Here the isolator isolates the propellant feed system at spacecraft ground potential from the discharge chamber, which is held at high voltage. Failure of such isolation due to gas breakdown within the isolator brings the ion source down to ground potential thereby precluding high voltage ion beam extraction.

\section{BACKGROUND}

Electrical isolation of the gas feed system from high voltage, in general, is typically achieved by using ceramic breaks in the feed line. Figure 2 illustrates such a device in its simplest configuration. The isolator allows gas to flow from the feedstock or propellant tank while at the same time electrically isolating the ion source from ground. Such insulators work particularly well at preventing electrical breakdown at modest voltages over a limited internal pressure range. Breakdown within such devices is a function of the product of the internal pressure and insulator gap as described by Paschen's law (see Fig. 3). ${ }^{3}$ One of the primary problems in isolator design is the maximization of the pressure range over which the device can hold off the minimum acceptable breakdown voltage.

The breakdown problem can be minimized by connecting a number of isolators in series. In this case, the standoff voltage is distributed between the series of isolators. This arrangement is configured such that the voltage required for breakdown across each cell greatly exceeds $\mathrm{V} / \mathrm{N}$ where $\mathrm{V}$ is the total standoff voltage and $\mathrm{N}$ is the number of cells in series. In order to operate at high voltage over a wide range of pressure, the number of cells required can be very large. ${ }^{2.4}$ This less compact design increases the overall cost and complexity of the isolator. Another approach to minimizing the likelihood of breakdown is to pack the interior of the isolator with alumina beads. ${ }^{5,6}$ Packing the isolator with beads minimizes the amount of free space in the isolator; therefore, the energy that a free electron can gain while traveling across a given open volume is minimized. Additionally, the beads provide added recombination surface area that would tend to be parasitic on a fledgling discharge. Sintering the beads to form a porous rod has also been investigated. ${ }^{5,6}$ These approaches are problematic from a number of standpoints:

(1) Increased device complexity due to the increased number of parts, (2) Fabrication process is complicated due to the presence of the beads (beads must be tightly packed to prevent the formation of orientation dependent voids) and (3) Conductive bridges can form on the beads or porus medium during the brazing process or a breakdown event. 
Magnetic insulation has been applied in the past to increase the breakdown voltage across vacuum gaps for high capacitance capacitor applications, for diodes used in intense ion beam production, and for magnetron designs used for very high power pulsed microwave radiation. ${ }^{7,8}$ In order to enhance the operating range of a conventional isolator and simplify the overall design, an augmented isolator utilizing magnetic insulation has been tested. In this present work, magnetic insulation has been found to significantly increase the breakdown voltage across the gas filled gap of a propellant isolator. This augmented model utilizes a conventional isolator immersed in a strong transverse magnetic field generated by commercially available rare-earth magnets. The layout of this component is illustrated in Figure 4 . The rare-earth magnets provide a strong field very compactly. The transverse magnetic field slows the development of the electron avalanche along the isolator axis thereby preventing the development of a breakdown event.

The transverse magnetic field isolator may be best explained by considering the transverse diffusion coefficient. Classically, the diffusion of electrons across a gap in the presence of a transverse magnetic field varies as $1 / \mathrm{B}^{2}$ in the limit of a large magnetic field, $B$. The ratio of the electron transverse diffusion coefficient to the unmagnetized diffusion coefficient may be expressed as: ${ }^{9}$

$$
\frac{D_{\perp}}{D_{a}}=\frac{1}{1+\left(\frac{w}{v}\right)^{2}}
$$

Here, $w$ is the electron cyclotron frequency and $v$ is the electron-neutral collision frequency. The effect of the magnetic field is to reduce the rate of diffusion perpendicular to the field lines. Electrons, constrained to the field lines, can diffuse only by collisions with neutrals or ions. In the presence of a transverse magnetic field and an axial electric field, the electron will undergo cycloid motion as illustrated in Figure 5. The trajectory of this orbit can be described by parametric equations:

$$
\begin{gathered}
x=a \cdot(1-\cos (w \cdot t)) \\
y=a \cdot(w \cdot t-\sin (w \cdot t))
\end{gathered}
$$

where $t$ is time and,

$$
a=\frac{m_{e} \cdot E}{e \cdot B^{2}}
$$

where $E$ is the electric field, $e$ is the elementary charge of the electron and $m_{e}$ is the mass of an electron.

On the first half of the cycloid orbit, the electron is accelerated by the electric field and therefore gains energy. During the latter half, it is de-accelerated by the electric field. Minimizing the distance over which the electron is accelerated can minimize the energy that an electron gains during the first half of a cycle. The maximum axial distance that the particle travels in the direction against the electric field is $2 \cdot a$. The path length, $2 \cdot a$, is inversely proportional to the square of the magnetic field strength. ${ }^{10}$ The effect of the magnetic field then is to reduce the energy that an electron gains in the electric field by reducing the acceleration path-length; that is, increasing the magnetic field decreases the distance over which work is done on an electron by the electric field. ${ }^{11}$

The utility of the magnetic isolator is now apparent. At low pressures where the mean-free path is long, the magnetic field constrains the orbit of a free electron to that of a cycloid. Because the electron can gain energy only over the first half of the orbit, if the field is sufficiently strong then electron will not gain enough energy to ionize the background gas. In this regard, avalanche formation can be dramatically suppressed using a transverse magnetic field. This reasoning is the primary motivation for this work. As the pressure increases, the total collision mean-free path becomes comparable to the path-length over which the electron is being accelerated. In this case, collisions with the background gas can significantly disrupt the cycloid motion. Under these conditions, the electron can gain net energy, ultimately obtaining the ionization potential. Breakdown can occur when the electron has 
gained a significant fraction of the ionization potential (breakdown may also be aided by step-wise events driven by metastable production at energies below the ionization potential). However, any discharge that manages to get started is significantly attenuated in the presence of a strong magnetic field due to reduced transverse diffusion.

\section{EXPERIMENTAL SET-UP}

A schematic of the experimental set-up is shown in Figure 6 . The experiments were conducted in a $41 \mathrm{~cm}$ diameter by $43 \mathrm{~cm}$ long bell jar. The bell jar was evacuated using a $25 \mathrm{~cm}$ cryo-pump which resulted in a base pressure in the high $10^{-8}$ Torr range.

The isolator's insulator section was made of $15.2 \mathrm{~mm}$ long alumina tube with an inside diameter of $3.2 \mathrm{~mm}$. The inlet and outlet end-caps of the isolator were constructed of Kovar. In order to map the isolator's performance over a broad pressure range, the isolator expellant end was attached to tubes with varying exit orifice diameters: $0.15,0.33$, and $0.762 \mathrm{~mm}$.

A static transverse magnetic field was imposed upon the isolator using four samarium-cobalt permanent magnets. The magnets were centered over the insulator section using an iron support arm as shown in Figure 4 . The support arm also aids in channeling magnetic flux into the region between poles. The peak field at the center of the isolator was measured to be $3.6 \mathrm{kG}$. The field near the end of the ceramic was measured to be $2.7 \mathrm{kG}$. Because the energy that an electron gains over a half-cycle is inversely proportional to the magnetic field, it is this reduced field near the ends of the ceramic that determines the breakdown voltage of the isolator.

A needle valve was used to adjust the flow of xenon (ion thruster propellant). During testing, the isolator flow rate, which was measured using an in-line flow meter, was varied between 0 and 5 standard cubic centimeters per minute at room temperature. Pressure associated with these flow rates was computed based on the volumetric flow and orifice diameter using the Poiseuille equation: ${ }^{12}$

$$
Q=\frac{\pi \cdot a^{4}}{8 \eta} \cdot P_{a} \cdot\left(P_{2}-P_{1}\right)
$$

Here, $Q$ is the flow potential, a is the radius of the channel, $\ell$ is the channel length, $\eta$ is the gas viscosity, $P_{a}$ is the arithmetic mean of $P_{2}$, the pressure in the channel, and $P_{1}$, the pressure in the vacuum vessel. Poiseuille s equation applies in the viscous regime where the Knudsen number $<0.01$. Because flow rate $F=Q /\left(P_{2}-P_{1}\right)$. the pressure inside the tube can be directly related the measured volumetric flow:

$$
F=\frac{\pi \cdot a^{4}}{8 \eta} \cdot P_{a}
$$

Breakdown was characterized as the threshold voltage at which the gas in the isolator hecome: highly conductive thereby allowing large currents to flow between high potential and ground. In order to delcrminc the breakdown characteristic of the isolator, the breakdown voltage of the propellant isolator was measured an a function of xenon flow rate. For these tests, the voltage was ramped from 0 to $4000 \mathrm{~V}$ using a high voltagc poucer supply. The current across the gap was measured via the high voltage power supply's ammeter. A breakidown is recorded when the $5 \mathrm{~mA}$ current limit of the high voltage power supply is tripped.

\section{EXPERIMENTAL RESULTS AND ANALYSIS}

Magnetic isolator testing entailed recording breakdown voltage as a function of internal pressure. Figure 7 illustrates the breakdown characteristic with and without the magnetic field present along with $B=0$ data from literature. ${ }^{13}$ The plots are essentially Paschen curves. The Paschen minimum for the case without the magnetic field is $\sim 600 \mathrm{~V}$, which is somewhat higher than the $450 \mathrm{~V}$ quoted in literature. ${ }^{13}$ The disparity between the Paschen data in Reference 13 and this work for the $B=0$ case is attributed to differences in electrode material type, electrode 
geometry and gas purity. As can be seen in Figure 7, the breakdown voltage increases significantly when the magnetic field is present. Two things are quite evident from the plots: (1) The Paschen minimum shifts to higher pressure by $\sim 10$ Torr when the transverse magnetic field is imposed and (2) The difference in breakdown voltages for the two cases at a given pressure is reduced at higher pressures ( $>10$ Torr), with this difference slowly decreasing in the limit of very high pressure. The first observation is quite desirable in that it demonstrates the ability of the imposed magnetic field to increase the operating range of the isolator. The second observation is associated with a reduction in the $\omega / v$ ratio as the electron-neutral collision frequency increases with increasing pressure. As pressure is increased, the effect of the imposed magnetic field becomes less and less.

The Paschen minimum for the transverse magnetic field isolator can be estimated. The minimum should occur when the mean-free path of the electron is equal to the integrated distance over which the electron is accelerated by the electric field. Under these conditions, the electron's cycloid motion is disrupted through a collision at maximum energy gain from the electric field. The electron can then repeat the process and increase its energy between collisions. Ultimately, the electron achieves enough energy to initiate electrical breakdown of the gas. At pressures beyond the Paschen minimum, energy gain between collisions is reduced and therefore the breakdown voltage increases again but at a slower rate.

The total distance actually traveled by the electron during the acceleration phase of the cycloid motion is s, where

$$
s=\int_{\pi}^{\frac{\pi}{2}} \sqrt{1+\left(\frac{d y}{d x}\right)^{2}} \cdot d x
$$

is the portion of the cycloid path integrated from $\omega t=\pi$ to $\omega t=\pi / 2$ as highlighted in Figure 5. Using low energy electron-neutral collision cross-section data, the electron-neutral mean-free path is calculated:

$$
l_{n e}=\frac{1}{n_{g a s} \cdot \sigma_{n e}}
$$

here, $l_{n e}$ is the electron-neutral mean-free path, $n_{\text {gas }}$ is the neutral gas density, and $\sigma_{n e}$ is the low energy electronneutral momentum cross section. ${ }^{14}$ The Paschen minimum for the magnetic isolator should occur when the ratio $s / l_{n e}$ is of order one. This ratio was calculated at a pressure of 10 Torr (Paschen minimum was determined experimentally to occur at 10 Torr) and a transverse field of $2.7 \mathrm{kG}$, the minimum field along the isolator ceramic. A plot of this curve is shown in Figure 8.

Upwards from $1250 \mathrm{~V}$, the ratio increases monotonically as a function of isolator voltage. The ratio behavior below $1250 \mathrm{~V}$ is due to the complicated structure of the low energy electron-neutral collision cross-section due to the Ramsuer effect. ${ }^{15}$ The calculated ratio is approximately unity at an isolator voltage of $2350 \mathrm{~V}$. This calculated value is within 4 percent of the measured $2250 \mathrm{~V}$ minimum of the magnetic isolator.

It should be pointed out that this calculation was also repeated for an isolator with a reduced-size insulator section ( $7.6 \mathrm{~mm}$ long). Here the minimum breakdown voltage was measured to be $\sim 1340 \mathrm{~V}$ at 12 Torr. The minimum voltage is reduced as expected due to the larger electric field. This value deviated from the calculated minimum breakdown voltage $(1200 \mathrm{~V})$ by $\sim 10$ percent. The measured deviations of the calculated minimum breakdown voltage from the experimentally measured value can be attributed in part to uncertainty in collision cross-sections, which can be as high as 20 to 30 percent. ${ }^{14}$ The upper limit on the uncertainty on the measured voltage value at which breakdown occurs is estimated to be on the order of a few percent. These uncertainties contribute in part to the deviations of the calculated value from experiment.

From this analysis, it can be seen that the isolator electric field and magnetic field are the two parameters that can be varied to optimize the overall performance. Increasing the operating range of the magnetic propellant isolator could be achieved by simply increasing the transverse magnetic field strength and reducing the electric field. Increasing the length of the insulator section would decrease the electric field and therefore reduce the acceleration distance $2 \cdot$ a. In this respect, the isolator can be optimized such that the voltage at which the ratio $s / l$ is unity is maximized. 


\section{CONCLUSIONS}

An enhanced propellant isolator has been investigated for high voltage applications. The concept utilizes a strong magnetic field to increase isolator breakdown voltage. The increase in breakdown voltage is attributed to the magnetic field-reduced path-length over which the electron may gain energy from the electric field. All in all, the transverse magnetic field can be used increase the voltage range that the isolator can safely stand off while at the same time deliver propellant gas.

\section{REFERENCES}

1. Nakanishi, Shigeo, NASA TMX-1579, 1968.

2. Mantenieks, Maris A., NASA TMX-71422, 1973.

3. Papoular, R., Electrical Phenomena in Gases, American Elsevier Publishing, NY, pp. 113-122, 1965.

4. Campbell, J.W., Bechtel, R.T., and Brophy, J.R., J. Spacecraft and Rockets, vol. 21, no. 4, pp. 321-322, 1984.

5. Pye, J.W., J. Spacecraft and Rockets, vol. 10, no. 2, pp. 106-112, 1973.

6. Fearn, D.G. and Pye, J.W., NASA A87-10544, 1986.

7. Winterberg, F., Phys. Rev. vol. 174, no. 1, pp. 212-219, 1968.

8. Lovlace, R.V., and Ott, E., Phys. Fluids, vol. 17, no. 6, pp. 1263-1268, 1974.

9. Chen, F., Introduction to Plasma Physics, Plenum Press, New York, pp. 169-174, 1984.

10. Lev A. Arzimovich, Elementary Plasma Physics, Blaisdell Publishing Company, New York, pp. 44-45, 1965.

11. Rajapandiam, S. and G.R. Govinda Raju, Proceedings of the $2^{\text {nd }}$ International Conference on Gas Discharges, pp. 169-170, 1972.

12. Dushman, S., Scientific Foundations of Vacuum Technology, J. Wiley and Sons, NY, pp. 80-1 17, 1962.

13. Guseva, L.G., Proceedings of the $9^{\text {th }}$ International Conference on Phenomena in Ionized Gases, p. 135, 1969.

14. Hayashi, Makoto, J. Phys. D: Appl. Phys., vol. 16, pp. 581-589, 1983.

15. Liboff, R., Introductory Quantum Mechanics, Addison Wesley, NY, pp. 233-238, 1992.

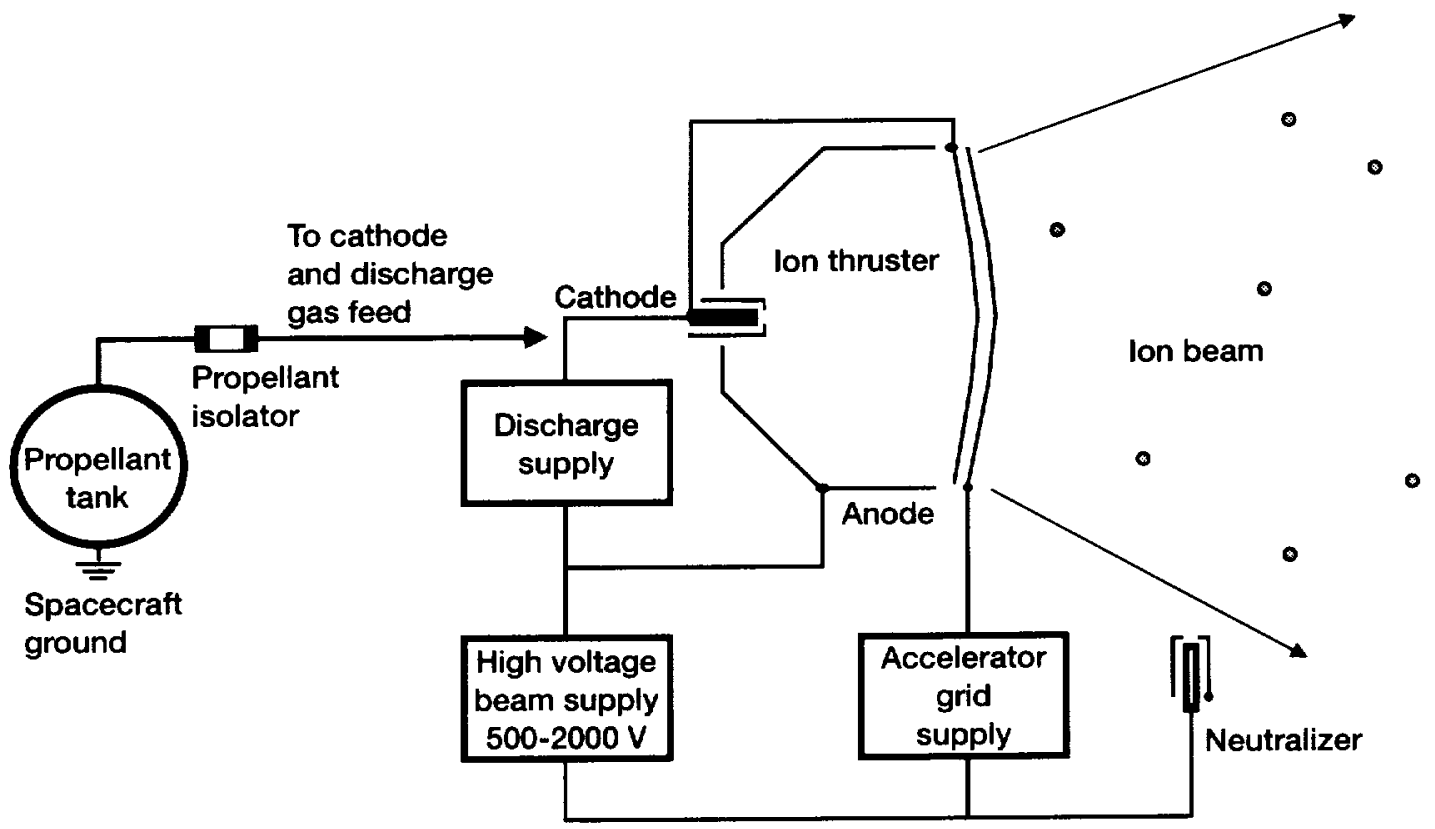

Figure 1.-lon engine power supply schematic illustrating propellant feed-line isolation from spacecraft ground. 


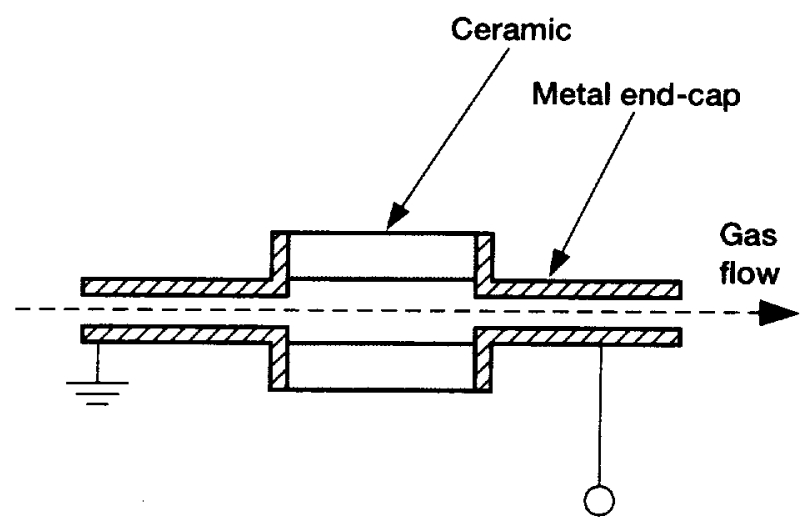

High voltage

Figure 2.-Side view cross-section of a simplified propellant isolator (cylindrically symmetric about axis along length).

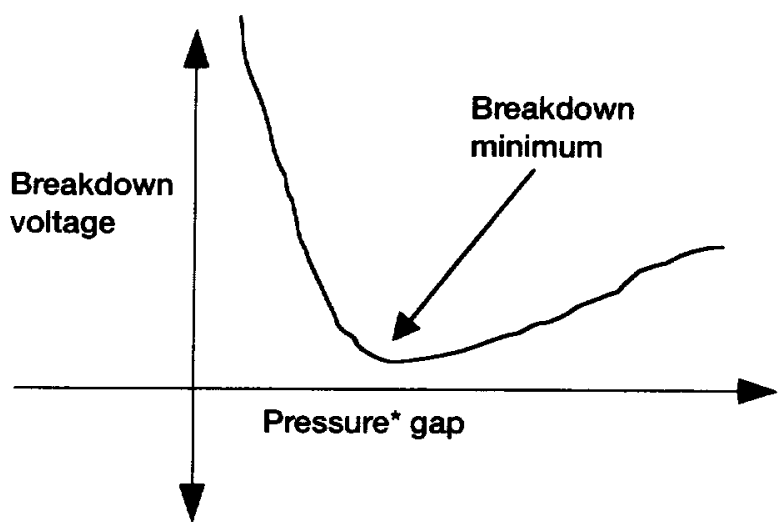

Figure 3.-Idealized Paschen curve for gas breakdown. 


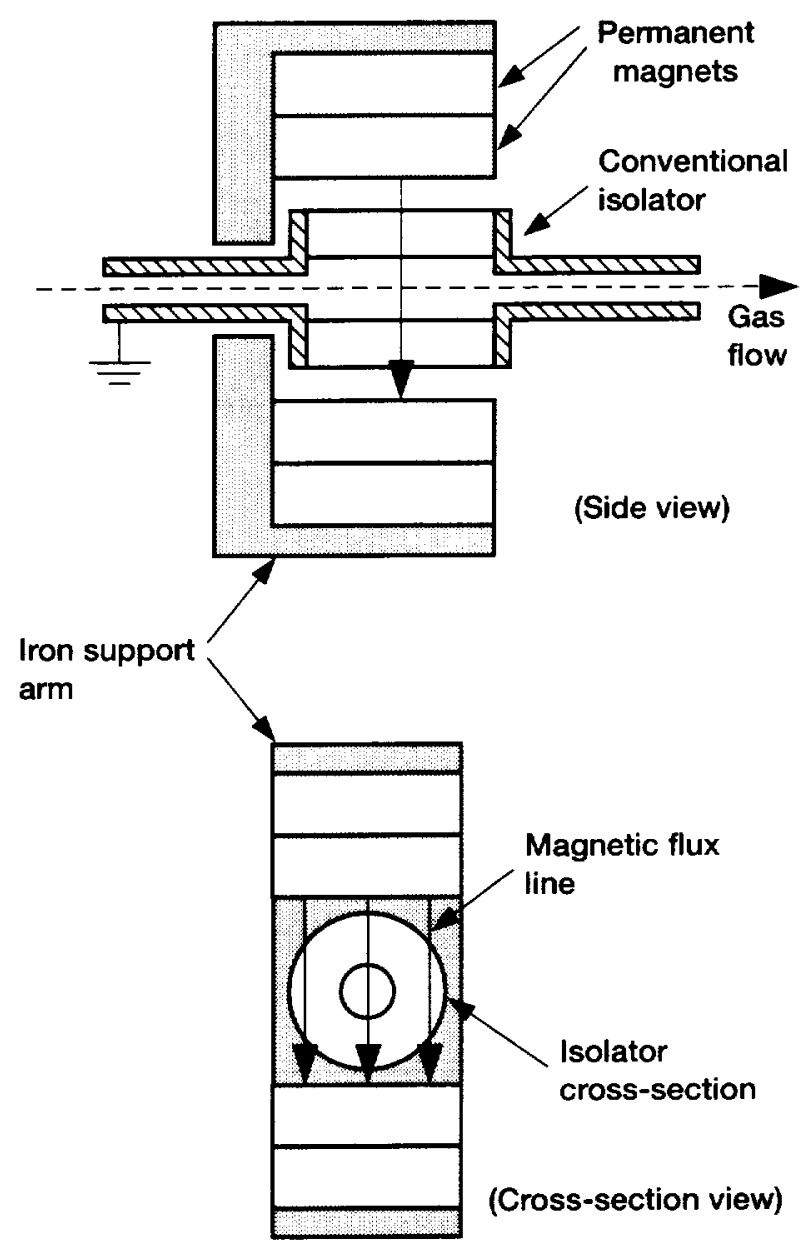

Figure 4.-Transverse magnetic field propellant isolator 


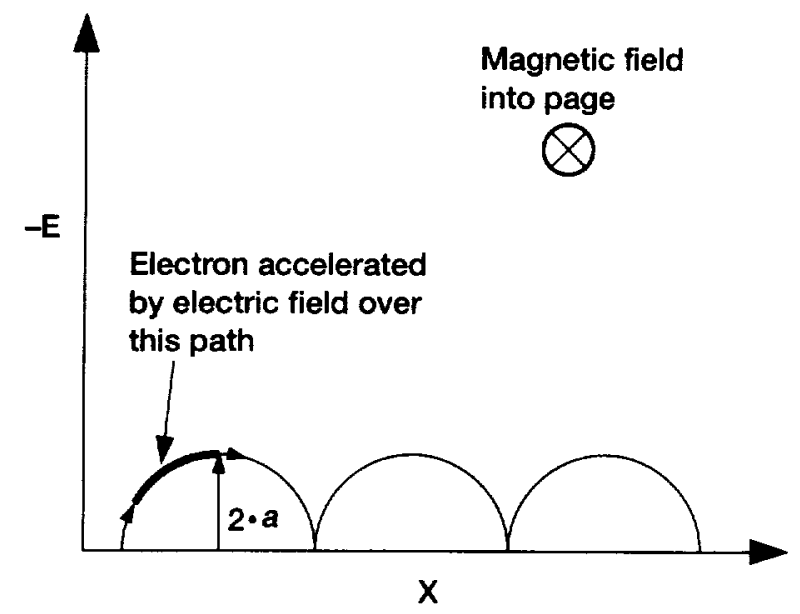

Figure 5.-Electron undergoing cycloid motion under the influence of a transverse magnetic field in the presence of an axial electric field.

High voltage power supply

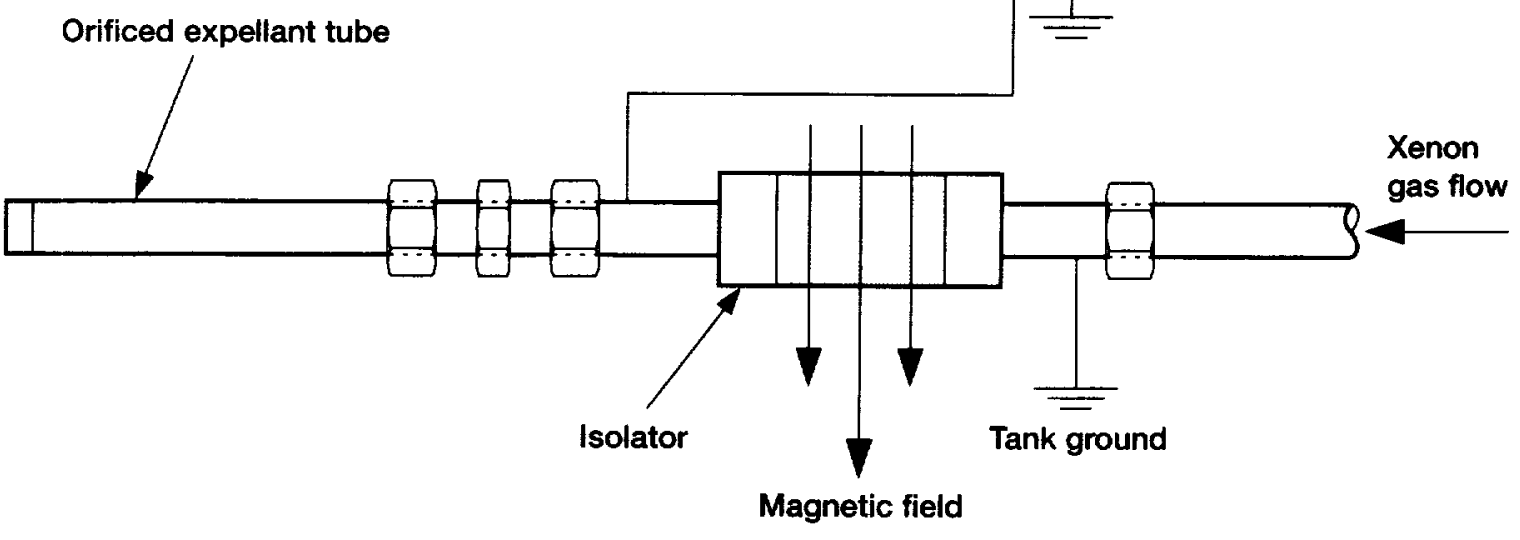

Figure 6.-Experimental set-up. 


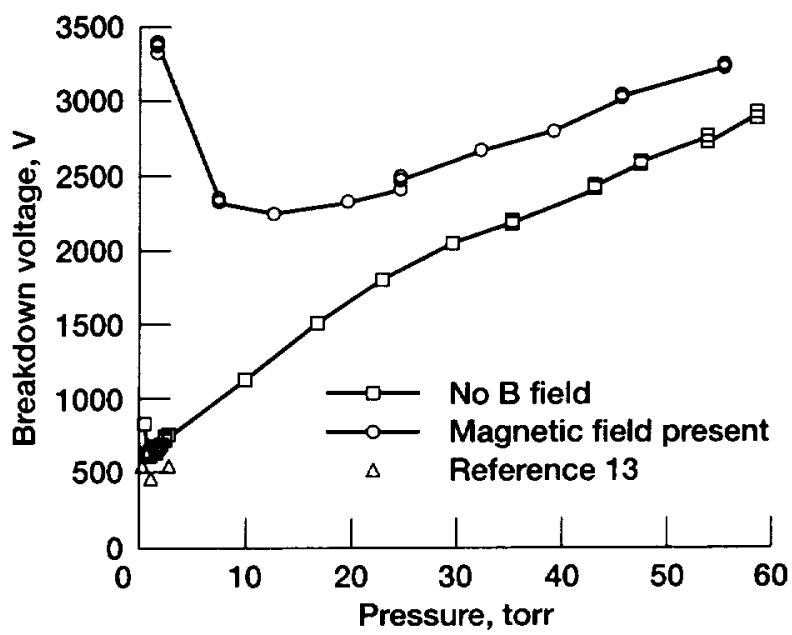

Figure 7.-Breakdown curves for isolator with and without transverse magnetic field.

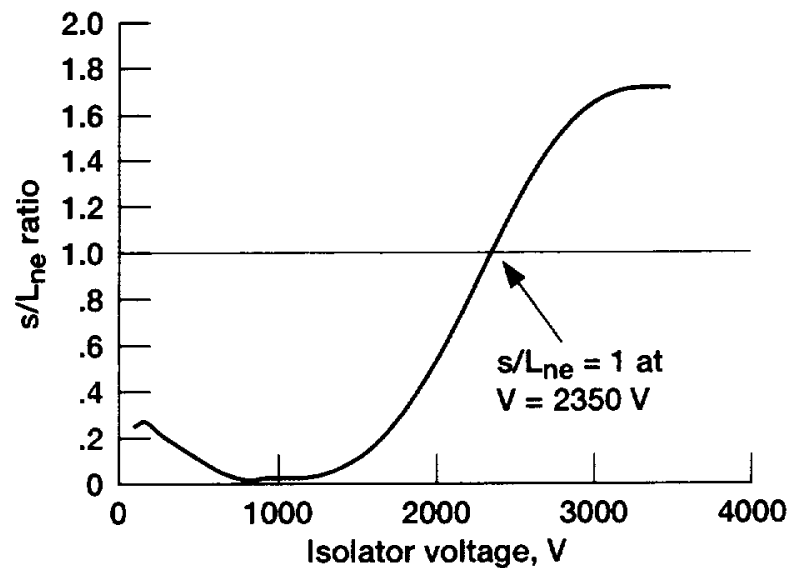

Figure 8.-Ratio of $s$ to electron-neutral mean free path. 
Public reporting burden for this collection of information is estimated to average 1 hour per response, including the time for reviewing instructions, searching existing data sources, gathering and maintaining the data needed. and completing and reviewing the collection of information. Send comments regarding this burden estimate or any other aspect of this collection of information, including suggestions for reducing this burden, to Washington Headquarters Services, Directorate for Intormation Operations and Reports, 1215 Jefferson Davis Highway, Suite 1204, Artington, VA 22202-4302, and to the Office of Management and Budget, Paperwork Reduction Project (0704-0188), Washington, DC 20503.

\begin{tabular}{|l|c|c|}
\hline 1. AGENCY USE ONLY (Leave blank) & $\begin{array}{c}\text { 2. REPORT DATE } \\
\text { August } 2000\end{array}$ & $\begin{array}{r}\text { 3. AEPORT TYPE AND DATES COVERED } \\
\text { Technical Memorandum }\end{array}$
\end{tabular}

\section{TITLE AND SUBTITLE}

Transverse Magnetic Field Propellant Isolator
WU-632-6B-1B-00

8. PERFORMING ORGANIZATION REPORT NUMBER

E-12378

John H. Glenn Research Center at Lewis Field

Cleveland, Ohio 44135-3191 5. FUNDING NUMBERS

John E. Foster

\section{PERFORMING ORGANIZATION NAME(S) AND ADDRESS(ES)}

National Aeronautics and Space Administration

9. SPONSORINGMONITORING AGENCY NAME(S) AND ADDRESS(ES)

10. SPONSORINGMONITORING

National Aeronautics and Space Administration

Washington, DC 20546-0001 AGENCY REPORT NUMBER

NASA TM-2000-210333

11. SUPPLEMENTARY NOTES

Responsible person, John E. Foster, organization code 5430, (216) 433-6131.

12a. DISTRIBUTION/AVAILABILITY STATEMENT

12b. DISTRIBUTION CODE

Unclassified - Unlimited

Subject Categories: 20 and 70

Distribution: Nonstandard

This publication is available from the NASA Center for AeroSpace Information. (301) 621-0390.

13. ABSTRACT (Maximum 200 words)

An alternative high voltage isolator for electric propulsion and ground-based ion source applications has been designed and tested. This design employs a transverse magnetic field that increases the breakdown voltage. The design can greatly enhance the operating range of laboratory isolators used for high voltage applications.

\section{SUBJECT TERMS}

15. NUMBER OF PAGES

15

16. PRICE CODE

$\mathrm{A03}$

\begin{tabular}{|c|c|}
\hline $\begin{array}{c}\text { 17. SECURITY CLASSIFICATION } \\
\text { OF REPORT }\end{array}$ & $\begin{array}{c}\text { 18. SECURITY CLASSIFICATION } \\
\text { OF THIS PAGE } \\
\text { Unclassified }\end{array}$ \\
Unclassified
\end{tabular}

NSN 7540-01-280-5500
19. SECUAITY CLASSIFICATION OF ABSTRACT

Unclassified
20. LIMITATION OF ABSTRACT 